\title{
The Influence of Cheerleading Exercises on the Development of Power Qualities of Intermediate Grade Schoolgirls
}

\author{
Dr. RidaTrad, Dr. MazenMroueh \\ Assistant Professor, Faculty of Pedagogy, Lebanese University
}

\begin{abstract}
The indexes of the development of power qualities and the influence of cheerleading exercises on their development for the middle grade schoolgirls are given in the article. The development level of power qualities was determined using the test results: body lifting to seated position from the initial position "lying flat on back", three jumps on one foot moving forward, pulling up on the lower crossbar. According to the results, this study has proved the positive influence of cheerleading exercises on the development level of power qualities of the 8th and 9th grades schoolgirls; therefore, physical training teachers can promote the cheerleading exercises in the educational process
\end{abstract}

Keywords: power abilities, cheerleading exercises, schoolgirls.

\section{INTRODUCTION}

Modern studies of the health condition and physical development of children show that these parameters deteriorate every year. Such condition of the younger generation is explained by the decreased motive activity. Motive activity was proved to be the major component of healthy life style, and the concept of "motive activity" reflects the socially motivated attitude towards physical culture and health (Balsevich V. K. 1997). Therefore, the present condition of health and physical development of schoolchildren makes it necessary to improve the quality of physical training of the schoolchildren.

\subsection{Body}

\subsubsection{Analysis of the Latest Publications}

For the last decade, there is a considerable increase of children with health distress. A number of authors (Krutsevich T. Yu., 2003; Lysiak V. M., 2006.Podrygalo L. V., 2014) state that about 90\% schoolchildren have certain health distress by the end of the study at school, mainly caused by their limited motive activity. Physical training is known to play a significant role in strengthening of health and comprehensive development of the younger generation. However, according to some researchers (Roters T. T., 2006; Stepanova I. V., 2007; Moskalenko N. V., 2007; Kibalnik O. Yu., 2008), today physical training lessons are ineffective and uninteresting. In this connection, physical training process in the secondary schools has to be improved.

The works $(1,5,9,10)$ deal with the issue of optimization of physical training process by changing the structure of the physical training lessons. However, these works are devoted to the influence of various facilities and methods on the level of physical fitness, functional condition and do not cover the issue of influence of cheerleading exercises on the development level of power qualities of middle grade children, which is the reason of our research.

* Objective of the study: Defining the degree of influence of cheerleading exercises on the power qualities of the schoolgirls of intermediate grade.

* Methods of the Study: Theoretical analysis and generalization of research and methodical literature, teachers' observations, pedagogical experiment, pedagogical testing, and methods of mathematical statistics.

The tests elaborated by Sergiyenko L. P. (2002), Romanenko V. A. (2005) were used to determine the development level of power qualities of schoolgirls. Pulling up on the low crossbar (number of times), 
The Influence of Cheerleading Exercises on the Development of Power Qualities of Intermediate Grade Schoolgirls

body lifting into seated position from the initial position "lying flat on back" (number of times per 1 minute), three jumps on one foot moving forward (m) were used as the test power tasks.

* Organization of the study: The research was conducted at a secondary Lebanese school (Khalil Jradi Public High School). Fifty schoolgirls of $8-9$ grades included into the study were divided into two experimental and two control groups. The participants of the pedagogical experiments were practically healthy and were under the supervision of doctors.

The research was conducted during eight months of 2015 -2016 school year. At the first stage, the preliminary testing of power fitness level was performed. At the second stage, the final testing was conducted with the purpose to determinate the influence of cheerleading exercises on the development level of power qualities.

During the study, the schoolgirls of the control groups were practicing the generally accepted school program, and the schoolgirls of the experimental group were practicing the elaborated program combining the basic and variant components. The ratio of base to variant components was $1: 2$; that is, once a week the students were practicing the school program, and were doing cheerleading twice a week. During the physical training lessons in the experimental groups, the amount, speed and complication of the performed cheerleading exercise complexes was gradually increasing. The load changed taking into account the physical fitness and the individual characteristics of the schoolgirls. The cheerleading exercises were included into the basic and preparatory parts of a lesson, in the system of the organized breaks and as the homework.

* Results of the study: The analysis of the results obtained in the age - related aspect showed the advantage of the results of 9th grade girls over the results of 8th grade girls. However, these differences are mainly unreliable ( $>0.05)$, except for the parameters of speed and power fitness (three jumps on one foot moving forward), that had reliable differences $(\mathrm{p}<0.001)$. Comparison of the values in the experimental and control groups showed no statistically reliable differences that characterized the homogeneity of initial values (Table 1).

Table1. Age-related parameters of power qualities of 8-9 grades schoolgirls before and after the experiment

\begin{tabular}{|c|c|c|c|c|c|}
\hline \multirow{2}{*}{ Parameter } & $8^{\text {th }}$ grade & $9^{\text {th }}$ grade & \multirow{2}{*}{$\mathbf{T}_{\text {st }}$} & \multirow{2}{*}{$\mathbf{T}_{\mathrm{cr}}$} & \multirow{2}{*}{$\mathbf{P}$} \\
\hline & \multicolumn{2}{|c|}{$\mathbf{X} \pm \mathrm{m}$} & & & \\
\hline \multicolumn{6}{|c|}{ Before the experiment } \\
\hline \multicolumn{6}{|c|}{ Experimental groups } \\
\hline Three jumps on one foot moving forward $(\mathrm{cm})$ & $432 \pm 2016$ & $535.7 \pm 14.0$ & 4.4 & 2.16 & $<0.05$ \\
\hline Pulling up on a low cross-bar (number of times) & $16 \pm 1.0$ & $18 \pm 0.9$ & 1.15 & 2.16 & $>0.05$ \\
\hline $\begin{array}{l}\text { Body lifting into the seated position from the initial } \\
\text { position "lying flat on back" (number of times) }\end{array}$ & $44.6 \pm 1.6$ & $45.1 \pm 2.4$ & 0.2 & 2.16 & $>0.05$ \\
\hline \multicolumn{6}{|c|}{ Control groups } \\
\hline Three jumps on one foot moving forward $(\mathrm{cm})$ & $394.3 \pm 13.9$ & $487.1 \pm 17.1$ & 3.4 & 2.16 & $<0.05$ \\
\hline Pulling up on a low cross-bar (number of times) & $12 \pm 2.0$ & $17.4 \pm 1.5$ & 1.9 & 2.16 & $>0.05$ \\
\hline $\begin{array}{l}\text { Body lifting into the seated position from the initial } \\
\text { position "lying flat on back" (number of times) }\end{array}$ & $42.8 \pm 2.2$ & $49 \pm 2.9$ & 1.4 & 2.16 & $>0.05$ \\
\hline \multicolumn{6}{|c|}{ After the experiment } \\
\hline \multicolumn{6}{|c|}{ Experimental groups } \\
\hline Three jumps on one foot moving forward $(\mathrm{cm})$ & $442 \pm 17.4$ & $542.8 \pm 13.3$ & 4.86 & 2.16 & $<0.05$ \\
\hline Pulling up on a low cross-bar (number of times) & $16.7 \pm 0.8$ & $18.5 \pm 0.7$ & 1.62 & 2.16 & $>0.05$ \\
\hline $\begin{array}{l}\text { Body lifting into the seated position from the initial } \\
\text { position "lying flat on back" number of times) }\end{array}$ & $33.8 \pm 1.5$ & $46.5 \pm 1.7$ & 0.72 & 2.16 & $>0.05$ \\
\hline \multicolumn{6}{|c|}{ Control groups } \\
\hline Three jumps on one foot moving forward $(\mathrm{cm})$ & $398.9 \pm 13.6$ & $496.4 \pm 14$ & 3.81 & 2.16 & $<0.05$ \\
\hline Pulling up on a low cross-bar (number of times) & $12.4 \pm 1.86$ & $18 \pm 1.1$ & 1.89 & 2.16 & $>0.05$ \\
\hline $\begin{array}{l}\text { Body lifting into the seated position from the initial } \\
\text { position "lying flat on back" number of times) }\end{array}$ & $44.1 \pm 1.8$ & $50 \pm 2.4$ & 1.5 & 2.16 & $>0.05$ \\
\hline
\end{tabular}

The analysis of the results of the study of the development level of schoolgirls' power qualities in the experimental groups after the effect of cheerleading exercises (Table 2) showed that all the values reflecting the development level of schoolgirls' power qualities improved for the girls of $8^{\text {th }}$ and $9^{\text {th }}$ grade at a reliable value $(\mathrm{p}<0.01)$. 
Table2. The parameters of development of the $8^{\text {th }}$ and $9^{\text {th }}$ grade schoolgirls' power qualities in EG and CG before and after the experiment

\begin{tabular}{|c|c|c|c|c|c|c|}
\hline \multirow{2}{*}{ Parameter } & Before the exp. & After the exp. & \multirow[b]{2}{*}{$\mathbf{T}_{\mathrm{st}}$} & \multirow{2}{*}{$\mathbf{T}_{\mathrm{cr}}$} & \multirow{2}{*}{\multicolumn{2}{|c|}{$\mathbf{P}$}} \\
\hline & \multicolumn{2}{|l|}{$X \pm m$} & & & & \\
\hline \multicolumn{7}{|c|}{ Experimental groups } \\
\hline \multicolumn{7}{|c|}{$8^{\text {th }}$ grade } \\
\hline \multicolumn{2}{|c|}{ Three jumps on one foot moving forward $(\mathrm{cm})$} & \multicolumn{2}{|c|}{$442 \pm 17.4$} & 2.68 & 2.16 & $<0.01$ \\
\hline $\begin{array}{l}\text { Pulling up on a low cross-bar } \\
\text { (number of times) }\end{array}$ & $16 \pm 1.0$ & $16.7 \pm 0.8$ & 2.01 & 2.16 & $>0.05$ & \\
\hline $\begin{array}{l}\text { Body lifting into the seated position } \\
\text { from the initial position "lying flat on } \\
\text { back" (number of times) }\end{array}$ & $44.6 \pm 1.6$ & $44.8 \pm 1.5$ & 1 & 2.16 & $>0.05$ & \\
\hline \multicolumn{7}{|l|}{$9^{\text {th }}$ grade } \\
\hline $\begin{array}{l}\text { Three jumps on one foot moving } \\
\text { forward }(\mathrm{cm})\end{array}$ & $535.7 \pm 14$ & $542.8 \pm 13.3$ & 2.67 & 2.16 & $<0.01$ & \\
\hline $\begin{array}{l}\text { Pulling up on a low cross-bar } \\
\text { (number of times) }\end{array}$ & $18 \pm 0.9$ & $18.5 \pm 0.7$ & 2.91 & 2.16 & $>0.05$ & \\
\hline $\begin{array}{l}\text { Body lifting into the seated position } \\
\text { from the initial position "lying flat on } \\
\text { back" (number of times) }\end{array}$ & $45.1 \pm 2.4$ & $46.5 \pm 1.7$ & 1.45 & 2.16 & $>0.05$ & \\
\hline \multicolumn{7}{|c|}{ Control groups } \\
\hline \multicolumn{7}{|c|}{$8^{\text {th }}$ grade } \\
\hline $\begin{array}{l}\text { Three jumps on one foot moving } \\
\text { forward }(\mathrm{cm})\end{array}$ & $394.3 \pm 13.9$ & $398.9 \pm 13.6$ & 1.95 & 2.16 & $>0.05$ & \\
\hline $\begin{array}{l}\text { Pulling up on a low cross-bar } \\
\text { (number of times) }\end{array}$ & $12 \pm 2.0$ & $12.4 \pm 1.86$ & 1.47 & 2.16 & $>0.05$ & \\
\hline $\begin{array}{l}\text { Body lifting into the seated position } \\
\text { from the initial position "lying flat on } \\
\text { back" number of times) }\end{array}$ & $40.8 \pm 2.2$ & $44.1 \pm 1.8$ & 1.4 & 2.16 & $>0.05$ & \\
\hline \multicolumn{7}{|c|}{$9^{\text {th }}$ grade } \\
\hline $\begin{array}{l}\text { Three jumps on one foot moving } \\
\text { forward }(\mathrm{cm})\end{array}$ & $487.1 \pm 17.1$ & $496.4 \pm 14$ & 2.15 & 2.16 & $>0.05$ & \\
\hline $\begin{array}{l}\text { Pulling up on a low cross-bar } \\
\text { (number of times) }\end{array}$ & $17.4 \pm 1.5$ & $18 \pm 1.1$ & 0.16 & 2.16 & $>0.05$ & \\
\hline $\begin{array}{l}\text { Body lifting into the seated position } \\
\text { from the initial position "lying flat on } \\
\text { back" number of times) }\end{array}$ & $49 \pm 2.9$ & $50 \pm 2.4$ & 1.52 & 2.16 & $>0.05$ & \\
\hline
\end{tabular}

An exception was made for the parameter of abdominal muscle strength for both groups and the parameters of hands strength of the $8^{\text {th }}$ grade girls where the changes were not reliable $(p>0.05)$.

The parameters of speed and power qualities of the $8^{\text {th }}$ grade girls improved by $2.4 \%$ and those of the $9^{\text {th }}$ grade girls improved by $1.3 \%$; the hands' muscles strength improved by $4.2 \%$ and $2.7 \%$; the parameters of abdominal muscle strength improved by $0.5 \%$ and $3 \%$, respectively.

Considering the results of testing the power indexes after the experiment in the age-related aspect revealed that the character of differences remains similar as compared to the initial data. The results of the $9^{\text {th }}$ grade girls exceeded the parameters of the $8^{\text {th }}$ grade girls in speed and power qualities $(\mathrm{p}<0.001)$.

The results of the schoolgirls in the control groups showed no reliable changes ( $p>0.05)$.

\section{CONCLUSION}

On the basis of study materials, the conclusions can be made as follows:

- The primary parameters of development level of power qualities of $8^{\text {th }}$ and $9^{\text {th }}$ grades schoolgirls have no reliable differences, except for the parameters of speed and power qualities, where the age - related differences are reliable $(\mathrm{p}<0.01)$.

- The parameters of speed and power qualities reliably improved in the experimental group after the experiment $(\mathrm{p}<0.01)$. Other power parameters also improved; however, these improvements are not reliable $(\mathrm{p}>0.05)$. 
- The conducted study proved positive influence of cheerleading exercises on the development level of power qualities of the $8^{\text {th }}$ and $9^{\text {th }}$ grades schoolgirls, which enables to recommend to the physical training teachers to inculcate the cheerleading exercises in the educational process.

\section{REFERENCES}

[1] Bala, T.M.; Maslyak, I.P., (2009): "Dynamics of the Physical Development of the 8-9 Grade Schoolgirls Inspired by Cheerleading", Slobozhansk Scientific Sports Bulletin. Kharkov State Academy of Physical Culture, Kharkov, N01, pp. 22-25.

[2] Balsevich, V.K.; Chernyshenko, Yu.K. Natalov, G.G., (1997):"Conversion of the main provisions of the theory of sports training in the process of physical education", Theory and practice of physical culture, , Is. 6.

[3] Kibalnik,O.Y.; (2008):"'Fitness-Technology as means of rising movement activity and physical preparation teem ages", pedagogic, psychology, medical - biological problems of physical training and sports.vol. 3, pp.78-81.

[4] Krutcevich,T.Yu., (2008): “Theory and Methodology of Physical Education “,Olympic Literature, Kiev, vol.2, pp 336.

[5] Lisyak, V.N., (2006):" Formation of Interest to physical Training in 6-11 Grade School Children", Synopsis of the author's abstract of the PH.D. Degree Thesis of Physical Education and Sport. Kharkov State Academy of Physical Culture, Kharkov; pp. 20.

[6] Podrigalo, L.V., (2004):" Prenosological Condition in Children, Teenagers and Youth: Diagnostics, Prognosis and Hygienic Correction", Kiev: Geneza, pp 200.

[7] Romanenko, V.A., (2005):" Diagnostics of Motor Abilities: Education Guidance", Donetsk National University, Donetsk, pp. 290.

[8] Sergienko, L.P. (2002):" Testing of Schoolboys' Motor Abilities”, Olympic Literature, Kiev, pp. 438.

[9] Serdyukov, O.E.; Vanbaum, Ya.S. ; (1997): "Research of the correlation of Physical Fitness and Some Indicators of the Students' Health Outcomes “, Modern problems of physical education and sport, Belgorod State University, Belgorod, pp. 285 - 288.

[10] Shesterova, L.E.; Terentieva, N.N. ; (2001):" Refinement of the Physical Education Lessons in Secondary Schools ", Slobozhansky Scientific Sports Bulleting// Kharkov State Academy of Physical Culture, Kharkov ; N01, pp. $20-21$. 